\title{
Safe use of streptokinase in myocardial infarction in patients aged 75 and over
}

\author{
Kalman Kafetz and Robert Luder*
}

\author{
Department of Medicine for Elderly People, Whipps Cross Hospital, London E11 1NR, UK
}

\begin{abstract}
Summary: We have given streptokinase to 73 patients aged 75 and over admitted to medical admission wards for elderly people using strict exclusion criteria. This was safe and free from significant adverse events by comparison with other studies. The average age of the patients was $\mathbf{7 8 . 2}$ years so they formed a relatively young group compared with all patients over 75 . There was a relatively long delay between presentation at the hospital and receipt of treatment.
\end{abstract}

\section{Introduction}

Myocardial infarction is an important clinical problem among people aged over 75 . In 1986, in the North West Thames region of the UK, there were 1,742 hospital admissions and 716 deaths of people of this age with this diagnosis. This group of patients formed $32 \%$ of all cases and $54 \%$ of all deaths from this cause. ${ }^{1}$ The value of thrombolytic treatment in patients over the age of 75 is not clear. Trials in the United States have systematically excluded patients over the age of $76 .{ }^{2}$ Of European trials, the GISSI-1 trial $^{3}$ showed no significant difference in mortality between patients aged over 75 treated with streptokinase and controls $(1,215$ patients; mortality $28.9 \%$ in streptokinase patients, $33.1 \%$ in controls). By contrast the ISIS$2^{4}$ study showed that, in patients aged over 70 , aspirin and streptokinase, both separately and together, improved mortality. In particular, the mortality in patients treated with both aspirin and streptokinase over the age of 70 was $15.8 \%$, significantly lower than the $23.8 \%$ mortality in age-matched controls. Lew and colleagues ${ }^{5}$ on the other hand studied 24 patients over 75 given streptokinase. Six had major haemorrhagic complications, four of which were fatal. They concluded that patients aged 75 and older should not be routinely treated with streptokinase.

In view of this conflicting data, we decided to institute a policy of using streptokinase for myocardial infarction in patients over the age of 75 with strict exclusion criteria and to evaluate our results.

Correspondence: K. Kafetz.

*Present address: North Middlesex Hospital, Sterling Way, London N18 1QX, UK.

Accepted: 2 March 1992

\section{Patients}

The Department of Medicine for Elderly People at $\frac{\mathbb{\Phi}}{3}$ Whipps Cross Hospital operates an age-related, $75 \frac{}{0}$ and over, admissions policy. ${ }^{6}$ This report describes 73 patients (37 men) who received streptokinase. $\overrightarrow{0}$ Seventy-one had an acute myocardial infarct usiag standard electrocardiogram (ECG) and enzyma criteria. Two presented with chest pain and ECG abnormalities but did not have a myocardial infarct in retrospect. The average age was $78.2 \stackrel{2}{2}$ years (range 75-88). Because of our initial caution $\frac{}{\Phi}$ we used strict criteria for treatment. The policy for $\stackrel{\varrho}{\Rightarrow}$ exclusion criteria in streptokinase use for the whole hospital is shown in Table I with extra exclusion criteria for patients over 75 noted. The main reason for the extra exclusion criteria was a concern over the induction of bleeding in patients with problems, relatively common among elderly people, of peptic ulcer (often painless), fracture, stroke or heart 3 . block needing pacing. These exclusion criteria were printed in the district formulary. Patients were treated if these criteria were absent and they had 0 evidence of myocardial infarction with onset of symptoms less than 24 hours before the start of $\frac{7}{0}$ treatment. Evidence of infarction was considered to be prolonged chest pain with typical ECG $N$ changes, prolonged chest pain with $1 \mathrm{~mm}$ ST N elevation in limb leads or $2 \mathrm{~mm}$ ST elevation or $\mathrm{N}$ depression in chest leads, and atypical symptoms $\frac{\omega}{\sigma}$ with classical acute ECG changes. If patients had prolonged chest pain with a normal ECG, they were not treated but the ECG was repeated in $3 \stackrel{\infty}{\rightarrow}$ hours and only treated if the ECG had changed as described.

Streptokinase was given at an average of $8.1 \stackrel{\vec{D}}{\circ}$ hours after the onset of symptoms (range 2-21 $\stackrel{\frac{\rho}{\Phi}}{\circ}$ 
Table I Exclusion criteria for streptokinase treatment

1. Severe heart failure

2. Active peptic ulceration

3. Known severe defect in haemostasis or coagulation

4. Known severe liver disease

5. Blood pressure on admission exceeding $180 / 100 \mathrm{mmHg}$

6. Major surgery within the past 6 days

7. Major trauma within the past 4 days

8. Cardiopulmonary resuscitation or central venous cannulation prior to institution of treatment

9. Pregnancy

*10. Cardiogenic shock

*11. Recent peptic ulceration or receiving treatment for peptic ulceration or other site or suspected site of gastrointestinal bleeding

*12. Trauma within past 4 weeks including limb or skull fractures

*13. Unstable bradyarrhythmia likely to need pacemaker

*14. Stroke within the last 3 months

*15. Other life-threatening illness or prognosis for life of 3 months or less

*Marks specific exclusion criteria for those 75 and over only.

hours) and an average of 3.2 hours after presentation at the Accident and Emergency Department (range 1-14 hours). After $100 \mathrm{mg}$ hydrocortisone was given intravenously, 1.5 MU streptokinase was given over 60 minutes in $50-250 \mathrm{ml}$ of $0.9 \%$ saline or $5 \%$ dextrose. Patients were not given heparin but did receive $150 \mathrm{mg}$ aspirin daily.

\section{Results}

There were 18 deaths $(24.7 \%, 95 \%$ confidence intervals $15.3-36.1 \%$ ).

Complications and comparisons with other published results are shown in Table II. The two studies used for comparison ${ }^{4,7}$ are the two largest to date. One patient had hypotension of such severity as to warrant a 'cardiac arrest call' but recovered with no resuscitation procedures. No patients had cerebral haemorrhages. Of the two patients with strokes, one had a computed tomographic scan confirming infarction. The other had a minor episode of right hemiparesis without impairment of consciousness the day after thrombolysis. There were minimal residual signs 3 months later. This contrasts with the catastrophic picture of cerebral haemorrhage in patients given streptokinase. ${ }^{4}$ The major haemorrhage in one patient may have been secondary to attempted resuscitation. This 75 year old lady was admitted with an anterior myocardial infarction and given streptokinase. Twenty-four hours later she developed chest and back pain followed by cardiac arrest. At post mortem the left pleural cavity contained $250 \mathrm{ml}$ of almost fresh blood, the pericardium contained a small old blood clot, there was no evidence of a dissecting aneurysm, the spleen was very soft and haemorrhagic, and there were areas of haemorrhage near the tail of the pancreas.

Of the patients with possible adverse reactions to streptokinase, two died. One was the patient described above. The other had a hypotensive reaction and on the next day had clinical evidence of ventricular septal rupture.

\section{Discussion}

Age is still seen as a contraindication to thrombolytic treatment, covertly as much as overtly. Pfeffer and colleagues, writing in 1991, studied 2,231 patients up to the age of 79 and noted: ${ }^{8}$ 'The influence of age on the use of thrombolytic therapy could not just be attributed to major differences among older patients since the frequency of thrombolytic use decreased progressively with age, even in the individuals younger than 70 years.' About a third of the coronary care units in the United Kingdom, have an age-related thrombolysis policy excluding patients from thrombolysis by varying age criteria. ${ }^{9}$ The British Heart Foundation survey of cardiologists and general physicians treating myocardial infarction in 1989 showed that $50 \%$ of the respondents denied thrombolysis to patients aged 75 and over. ${ }^{10}$ Our department has argued that one of the advantages of age-related geriatric medicine is to eliminate ageist bias in clinical policies. ${ }^{11}$ Gurwitz and colleagues ${ }^{2}$ felt that the prospect of an adequately sized, randomized, placebo-controlled trial in patients aged over 75 of thrombolysis in myocardial infarction was extremely unlikely as 4,000 patients would be needed if death were the major end-point. Baillie and Furniss have called for more data regarding current practices of thrombolysis in elderly patients with myocardial infarction to enable the establishment of optimal management policies. ${ }^{12}$

Our results show that, contrary to the experience of Lew and colleagues, ${ }^{5}$ it is possible to replicate the results of large trials in terms of safety of thrombolytic treatment in a district hospital setting among patients aged 75 and over. Lew and colleagues are cardiologists and our department is a specialist department of medicine for elderly people. This audit has encouraged us to persist with this treatment. However, the results raise a number of questions. The average age of the treated patients is younger than the average age of all our acute in-patients (about 84). Are we ourselves using 
Table II Side effects of streptokinase in this Whipps Cross series compared with the ISIS- 2 study ${ }^{4}$ and the ISG study. ${ }^{7}$ The comparative figures are for patients of all ages except for the figures for stroke in the ISG study which are for patients aged over 70. The one Whipps Cross patient with major haemorrhage may have been secondary to resuscitation (see text). The ISG figures show effects of alteplase (tPA) as well as streptokinase

\begin{tabular}{lcccc}
\hline Side effect & Whipps Cross & ISIS-2 & \multicolumn{2}{c}{ ISG } \\
\hline Hypotension & $10(13.7 \%)$ & $10 \%$ & $3.8 \%$ SK & $1.7 \%$ tPA \\
Strokes & $95 \%$ CI $6.8-23.8 \%$ & & & \\
& $2(3 \%)$ & $0.7 \%$ & $1.6 \%$ SK & $2.7 \%$ tPA \\
Febrile reactions & $2(3 \%)$ & $4.4 \%$ & $\begin{array}{l}\text { patients } \\
\text { 1.7\% SK }\end{array}$ & $\begin{array}{l}0.2 \% \text { tPA } \\
\text { Minor bleeds }\end{array}$ \\
Major bleeds & $4(5.5 \%)$ & $3.5 \%$ & $2.4 \%$ SK & $3.6 \%$ tPA \\
& $1(1.4 \%)$ & $0.5 \%$ & $0.9 \%$ SK & $0.5 \%$ tPA \\
\hline
\end{tabular}

age, albeit advanced age, as a covert selection criterion? Alternatively, is myocardial infarction in the very old not recognized sufficiently early for treatment, perhaps because of altered presentation? ${ }^{13}$ The vast majority of our patients presented with typical symptoms. There may be a higher prevalence among the very elderly of contraindications to streptokinase use. Furthermore, general practitioners may not refer some patients with myocardial infarction to hospital. ${ }^{14}$

There was a significant delay in treating these patients with an unusually long time between presentation in casualty and receiving treatment. The mean time of 3.2 hours contrasts with other reported times of 50-130 minutes. ${ }^{15}$ However, these times come from studies in centres where intensive research into thrombolysis in mainly young patients was taking place, an environment in which prompt treatment would be encouraged. $\frac{f}{\sigma}$ Nevertheless a further audit of this time interval 응 will be necessary to see if it has improved in an atmosphere of improved confidence in throm- $\omega$ bolysis for elderly people. Minimizing delay in $\mathbb{D}$ treating elderly people with thrombolysis after $\stackrel{\mathbb{\Phi}}{3}$ admission to hospital is particularly important because they usually call for medical help later afte the onset of symptoms than younger people. ${ }^{16}$

\section{Acknowledgements}

We thank our colleagues Drs Myriam Lugon, Geraldine $\bar{\partial}$ McElligott and Brian Rossiter for permission to study their patients and Dr Kathleen Thomas for the post $\stackrel{\mathbb{Q}}{\mathbb{Q}}$ mortem.

\section{References}

1. Greenbaum, R. Streptokinase in the management of acute myocardial infarction. Cardiol Practice 1990, 8: 15-18.

2. Gurwitz, J.H., Goldberg, R.J. \& Gore, J.M. Coronary thrombolysis for the elderly? JAMA 1991, 265: 1720-1723.

3. Gruppo italiano per lo studio della streptochinasi nell'infarto miocardico (GISSI). Effectiveness of intravenous thrombolytic treatment in acute myocardial infarction. Lancet 1986 , i: $397-401$.

4. ISIS-2 (Second International Study of Infarct Survival) Collaborative Group. Randomized trial of intravenous streptokinase, oral aspirin, both or neither among 17,187 cases of suspected myocardial infarction. Lancet 1987, i: 349-360.

5. Lew, A.S., Hod, H., Cercek, B., Shah, P.K. \& Ganz, W. Mortality and morbidity rates of patients older and younger than 75 years with acute myocardial infarction treated with intravenous streptokinase. Am J Cardiol 1987, 59: 1-5.

6. Mitchell, J., Kafetz, K. \& Rossiter, B. Benefits of effective hospital services for elderly people. Br Med J 1987, 295: 980-983.

7. The International Study Group. In-hospital mortality and clinical course of 20,891 patients with suspected acute myocardial infarction randomized between alteplase and streptokinase with or without heparin. Lancet 1990, 336: 71-75.

8. Pfeffer, M.A., Moyé, L.A., Braunwald, E. et al. Selection bias in the use of thrombolytic therapy in acute myocardial infarction. JAMA 1991, 266: 528-532.

9. Dudley, N.J. \& Burns, E. Age-related policies in coronary care units in the United Kingdom. Age Ageing 1991, $20 \mathrm{~N}$ (Suppl 1): 29.

10. Collins, R. \& Julian, D. British Heart Foundation surveys $N$ (1987 and 1989) of United Kingdom treatment policies for acute myocardial infarction. Br Heart $J$ 1991, 66: 250-255. $\omega$

11. Rossiter, B., Kafetz, K., Lugon, M. \& McElligott, G. O Geriatric medicine. Lancet 1989, ii: 506-507.

12. Baillie, S.P. \& Furniss, S.S. Thrombolysis for elderly patients - which way from here? Age Ageing 1991, 20: 1-2. 
13. Nadelmann, J., Frishman, W.H., Ooi, W.L. et al. Prevalence, incidence and prognosis of recognized and unrecognized myocardial infarction in persons aged 75 or older: the Bronx aging study. Am J Cardiol 1990, 66: 533-537.

14. Pell, A.C.H., Stuart, P.C., Stewart, M.J. \& Fraser, D.M. Home or hospital care for acute myocardial infarction? A survey of general practitioner's attitudes in the thrombolytic era? Br J Gen Pract 1990, 40: 323-325.
15. Pell, A.C.H., Miller, H.C., Robertson, C.E. \& Fox, K.A.A. Effect of 'fast track' admission for acute myocardial infarction on delay to thrombolysis. $\mathrm{Br}$ Med J 1992, 304: 83-87.

16. Rawles, J.M. \& Hailes, N.E. Patient and general practitioner delay in acute myocardial infarction. $\mathrm{Br}$ Med $J$ 1988, 296: 882-884. 